\title{
Accidental Hypothermia
}

\author{
PR Davis, $M$ Byers
}

\section{Introduction \\ This article reviews the aetiology of accidental hypothermia when it occurs secondary to an environ- mental or traumatic injury, and provides an update on the pre-hos- pital management of the condition. The issues surrounding transfer to definitive care and further manage- ment in the critical care setting are outlined.}

\section{The Historical Perspective}

During wartime, the plans for many military campaigns have failed to survive first contact with the elements. In $218 \mathrm{BC}$, the Carthaginian general Hannibal set off with his now famous forty war elephants, but also with 12,000 cavalry and 90,000 infantry, to traverse the Alps via the Col de Mont Cenis, into northern Italy. While this is portrayed as a great success, only about half of this army survived the march, the remainder died from what we would now term environmental injury along the way. Though Hannibal enjoyed initial military success with some spectacular victories in the countryside, he ultimately failed to march on Rome due to critical depletion of his force. Eventually Carthage fell and Rome was victorious.

At the height of his military powers in 1812, Napoleon marched on Moscow with an army of more than half a million men. The retreating Russian army had stripped the countryside bare of resources and so first of all the French army was starved of food, then winter arrived with a vengeance. The French army was decimated through a combination of poor diet and inadequate clothing and equipment in the face of persistent sub-zero temperatures and winds that increased the thermal losses from the soldiers. Less than 20,000 men eventually returned to France; over 480,000 troops had perished (1).

130 years later, Hitler advanced on Moscow at the beginning of the Russian winter. His confidence had been boosted by a series of early defeats over the Red Army. However 100,000 German soldiers suffered cold injury (about $10 \%$ of the whole army) in November and December 1941, and this resulted in around 15,000 amputations. The German advance was subsequently halted.

Records of death from immersion in cold water date back to ancient times. Circa 450 BC, Herodotus wrote of the sea borne expedition against Athens by the Persian general Mardonius. He clearly distinguished drowning from hypothermia, when he wrote, "Those who could not swim perished from that cause, others from cold (2). In spite of countless maritime disasters, the precise medical cause of death has been rarely noted. Death has commonly been ascribed to "drowning" or being "overcome by the sea". James Lind (1762) mentioned the dangers of collapse after rescue (3), and James Currie (1797) observed deterioration of his subjects before improvement (4). Little attention was paid to the observations by Lawrence Beesley (1912) (5). He was a survivor from the Titanic who noted that victims who were wearing lifebelts had died in calm but cold water, without having being submersed. The official cause of death was given as drowning, but was clearly due to immersion hypothermia. It was the inadequacies of life saving equipment during the Battle of the Atlantic in the Second World War that was the catalyst for scientific examination of the problem. On occasion, high profile tragedies such as the Fastnet race disaster of 1979 have stimulated further research and promoted periodic review of recommendations for safety clothing and equipment for mariners. The names of Surgeon Rear Admiral Frank Golden OBE Royal Navy and his colleagues at the Institute of Naval Medicine have become synonymous with such research.

Though the maritime environment presents hazards to military operations or adventurous training, equally activities in mountainous or snow-covered terrain will expose participants to hypothermia or cold injury. The network of physicians working in the European Alpine regions through the International Committee for Alpine Rescue (http://www.ikar-cisa.org), International Society for Mountain Medicine (http: www.ismmed.org) and the Union Internationale des Associations d'Alpinisme medical committee (International Mountaineering and Climbing Federation; http://www.uiaa.ch) have been instrumental in gathering data and publishing guidance for the pre-hospital triage and management of victims of deep hypothermia in the mountains (6). This may occur with or without associated injury, through isolation in the cold due to terrain or weather con- 
straints or delays due to the technical difficulty of a particular route. Climbers, but more particularly off-piste skiers or ski mountaineers are vulnerable to hypothermia following prolonged entrapment in a glacial crevasse as the result of a fall, or through burial under snow in an avalanche. Military mountain troops are subject to the same hazards. Particular credit must go to Professor Hermann Brugger, Dr Bruno Durrer and their colleagues. Being both doctors and professional mountain guides, and working in the European Alps as members of alpine rescue teams, they have personally attended several hundred cases of avalanche burial. This vast experience has been shared in several important publications(7-9). The principles guiding the resuscitation of victims of accidental hypothermia in the maritime or mountain environment may be applied to everyday emergency practice, even in an urban setting (10).

\section{Definitions}

Hypothermia is said to exist when the body core temperature (Tco) is below $35^{\circ} \mathrm{C}$. Arbitrarily it is classified as MILD (Tco 35 $32^{\circ} \mathrm{C}$ ), MODERATE (Tco $32-30^{\circ} \mathrm{C}$ ) or SEVERE $\left(\mathrm{Tco}_{\mathrm{C}}<30^{\circ} \mathrm{C}\right)$.

\section{Pathophysiology}

Hypothermia commonly results from an injury in a cold environment, immersion in cold water or a prolonged exposure to low temperatures without adequate protective clothing and equipment (11).

Muscular activity and the catabolic processes of the body produce heat; heat is lost by radiation, convection, conduction and evaporation (vaporisation) particularly of water vapour from the skin and lungs. Normal body temperature is a balance between heat production and heat loss. Within the body, enzyme systems operate optimally within a narrow temperature range, and the preservation of normal body functions depends on the body temperature being maintained within a narrow range. This process is termed thermoregulation. In mild hypothermia, thermoregulatory mechanisms operate fully in an attempt to combat the situation. If the condition is unchecked however, the thermoregulatory system diminishes until it fails, and death from hypothermia is generally from cardiorespiratory failure.

Hypothermia causes characteristic ECG changes (the Osborn J wave) and in severe hypothermia, patients are at risk of life threatening dysrythmias. The typical sequence is a progression from sinus bradycardia through atrial fibrillation (AF) to ventricular fibrillation (VF) and ultimately asystole (12). Rough patient handling or sudden changes in posture may provoke VF at any time in the severely hypothermic patient.
Initial tachypnoea is replaced by a decrease in respiratory rate and tidal volume, and bronchorrhea predisposes to aspiration pneumonia. The oxyhaemoglobin dissociation curve undergoes a leftwards shift impairing oxygen delivery to the tissues.

The central nervous system is progressively depressed with a corresponding decrease in conscious level. Mild incoordination progresses through agitation and irritation to lethargy and eventually coma. Decreased cerebral oxygen requirements may protect the brain against anoxic or ischaemic damage in hypothermia after cardiac arrest (13).

Cold diuresis occurs due to impaired renal concentration and an increased central intravascular volume due to peripheral vasoconstriction. Volume losses may be such that significant fluid resuscitation is required whilst managing the recovering victim.

Adrenoceptors become dysfunctional in severe hypothermia so vasoactive drugs are ineffective and may accumulate to toxic thresholds, then exerting their toxic effects upon rewarming and reperfusion (14) (e.g. epinephrine).

There is a plasma shift to the extravascular space, and the consequent haemoconcentration may lead to disseminated intravascular coagulation (DIC). Reversible platelet dysfunction occurs and the clotting time is prolonged due to derangement of the extrinsic pathway $(15,16)$.

The immobile hypothermic patient is prone to rhabdomyolysis and acute tubular necrosis may occur through myoglobinuria and renal hypoperfusion.

In the initial stages, increased insulin secretion and glycogenolysis mobilises glucose reserves, but hypoglycaemia supervenes as reserves are used up.

Acidosis occurs due to respiratory depression and hypercarbia, and lactic acid production through shivering and poor tissue perfusion.

Hepatic function is depressed leading to accumulation of drugs that normally undergo hepatic metabolism or detoxification.

Finally, the extremities are vulnerable to frostbite as a result of the peripheral vasoconstriction, hypoperfusion and haemoconcentration leading to 'sludging' of the red cells within the small blood vessels.

\section{Accidental Hypothermia In Trauma Patients}

From the late 1980s the 'Lethal Triad' of hypothermia, acidosis and coagulopathy has been identified as a major cause of morbidity and mortality in the critically injured patient. Patients are more likely to die in the Intensive Care Unit (ICU) from persistent acidosis and uncorrected coagulopathy, rather than in the Operating Room (OR) from failure to definitively repair a bowel injury, perform a complex vascular anastomosis or to achieve intermedullary fixation of a comminuted long 
bone fracture $(17,18)$.

The concept of Damage Control Surgery has evolved to embrace this philosophy. This is a form of surgical management that aims to do the minimum of surgery as rapidly as possible to save life or limb, recognising that the next phase in the ICU is every bit as crucial to the eventual survival of the patient.

Studies from urban trauma centres have shown that more than $50 \%$ of patients with penetrating injury are hypothermic upon admission to the ED, even when transport times from scene of wounding to hospital are less than fifteen minutes (19). This is predominantly due to the initial hypovolaemia associated with penetrating injury, or major visceral injury caused by blast or by blunt trauma. In an austere environment, one could easily imagine how the trauma patient might present in a hypothermic state.

Mortality has been shown to increase by as much as $50 \%$ in case matched trauma studies where patients are hypothermic compared to normothermic upon arrival (20).

Other than penetrating trauma to the abdomen or extremities, trauma patients at especially high risk for hypothermia include the very young and very old, the head injured patient (the thermostat mechanisms in the hypothalamus may be deranged) and the patient with a high spinal injury causing disruption to the sympathetic chain. These patients become poikilothermic and are unable to regulate their temperature control. Likewise burns patients have lost skin covering, and they may have a large surface area from which to haemorrhage heat. It is therefore imperative that measures are taken to prevent further heat loss in the injured patient, and where hypothermia already exists, the most appropriate method of rewarming is instituted at the earliest opportunity in order to minimise further morbidity or mortality (21).

\section{Responses To Cooling}

On exposure to cold the body responds by increasing heat output, which depletes energy stores, there is peripheral vasoconstriction, which directs the blood into the venae comitantes, heat is transferred from the arterial to the venous blood and this counter current exchange transfers heat back to the core. There is a relative increase in central blood volume, which leads to a diuresis, and there is a shift of fluid from intravascular to extravascular spaces.

The rate at which one becomes hypothermic is proportional to the interrelationship between increased heat loss, decreased heat production and decreased inflow of heat energy. Body fat or protective garments may attenuate heat loss, but wet and windy conditions may decrease effective clothing insulation by up to $90 \%$ (22). Shivering and exercise increase heat production and may arrest or attenuate the development of hypothermia. A high level of shivering heat production may continue for 4 to 6 hours. However if moderate or severe hypothermia supervenes, shivering will cease earlier, as it is centrally inhibited (23).

\section{The Aetiological Classification Of Hypothermia}

This follows from the variations in interaction between heat production, heat loss and ingress of heat energy.

\section{Acute hypothermia}

The cold stress is so severe, that increased thermogenesis cannot maintain equilibrium; the victim cools rapidly, but before the energy reserves are used and the intravascular fluid changes occur. This kind of hypothermia occurs for instance in the climber or off-piste skier, buried by snow in an avalanche, or entrapped within a narrow crevasse where body heat is very rapidly conducted away to the icy crevasse walls. The maritime scenario is of cold water immersion without adequate protective clothing. Here, the cold shock response occurs in the first 3 to 4 minutes. This initiates peripheral vasoconstriction, the gasp reflex, hyperventilation and tachycardia, and may lead to submersion and drowning, or cause vagal arrest of the heart. In survivors of the cold shock, hypothermia may take up to 30 minutes to develop(24). Survival time prediction is based on the interrelationship between the thermoregulatory response, clothing and insulation, sea temperature and sea conditions (25).

\section{Sub-acute hypothermia}

This is the hypothermia of a climber isolated in the mountains. There is a slow but continuous heat loss and the energy reserves become gradually depleted. The rate of onset is related to the patient's physical and mental condition, his equipment and the severity of the environmental conditions. Complex fluid shifts occur between the various body compartments, leading to hypovolaemia, and necessitating fluid resuscitation during rewarming.

\section{Sub-chronic hypothermia}

The classic example is of the elderly patient, immobilised through a fractured neck of femur sustained in a fall at home. It typically occurs during winter, when social circumstances preclude adequate heating of the residence. Hypothermia is slow in onset but complicated by depletion of energy reserves, rhabdomyolysis, acute renal failure, metabolic acidosis and hypovolaemia due to fluid compartment shifts. Resuscitation is challenged by cardiovascular instability, and by co-morbidities such as respiratory tract infection, which lead to high mortality rates in this sub group.

To place these classifications in a clinical context, the aetiology of a particular case is of relevance in determining the method of rewarming that is most suitable for that case. For example rapid rewarming of the elderly victim who is fluid deplete may precipitate 
cardiovascular collapse, and should be avoided.

\section{Pre-Hospital Care \\ Equipment}

Personal protective equipment (PPE) must be adequate for the task in hand, in what is likely to be an austere and challenging environment. If the practitioner is part of an organised response (mountain or maritime rescue; formal pre-hospital care organisation), then it is expected that patient monitoring, drugs and critical care equipment will be available. If an incident occurs during an expedition or deep military operation, then complex equipment is unlikely to be available and management decisions will be made on clinical assessment. In specific scenarios, it may be vital to assess the core temperature. In the field this should be done with an epitympanic low reading thermometer. Temperatures measured by the tympanic route correlate well with those measured by the oesophageal route (26). Oesophageal or urinary bladder electronic probes are considered to be the gold standard of critical care temperature monitoring; rectal probes have consistently been shown to not be as accurate, and in any case are not practicable in the field $(27,28)$.

\begin{tabular}{|l|l|l|}
\hline & Stage IV & Stage V \\
\hline Clinical Features & $\begin{array}{l}\text { Absent vital } \\
\text { signs } \\
\text { Thorax compressible } \\
\text { pliable } \\
\text { Abdominal muscles }\end{array}$ & $\begin{array}{l}\text { Absent vital } \\
\text { signs } \\
\text { Non-compressible } \\
\text { thorax } \\
\text { Rigid abdomen }\end{array}$ \\
\hline ECG Features & $\begin{array}{l}\text { Ventricular fibrillation } \\
\text { (VF) }\end{array}$ & $\begin{array}{l}\text { Asystole } \\
\text { or asystole }\end{array}$ \\
\hline Core Temperature $^{(\mathrm{Tco})}$ & Greater than $13^{\circ} \mathrm{C}$ & Less than $13^{\circ} \mathrm{C}$ \\
\hline Serum Potassium & $\begin{array}{l}\text { Below } 12 \mathrm{mmol} / 1 \\
\mathrm{mmol} / 1\end{array}$ & Greater than 12 \\
\hline
\end{tabular}

\begin{tabular}{|lll|}
\hline Stage I & Patient alert and shivering & $\left(\mathrm{Tco} 35-32{ }^{\circ} \mathrm{C}\right)$ \\
\hline Stage II & Patient drowsy and not shivering & $\left(\mathrm{Tco} 32-28^{\circ} \mathrm{C}\right)$ \\
\hline Stage III & $\begin{array}{l}\text { Patient unconscious, but with vital } \\
\text { signs present }\end{array}$ & $\left(\mathrm{Tco} 28-24{ }^{\circ} \mathrm{C}\right)$ \\
\hline Stage IV & Absent vital signs; apparent death & $\left(\mathrm{Tco} 24-13^{\circ} \mathrm{C}\right)$ \\
\hline Stage V & Death due to irreversible hypothermia & $\left(\mathrm{Tco}<13{ }^{\circ} \mathrm{C}\right)$ \\
\hline
\end{tabular}

$(\mathrm{Tco}=$ Core Temperature $)$

\section{Staging Of Hypothermia In The Field} According To Clinical Features

Various systems exist for the field staging of hypothermia, but the 'Swiss' (Swiss Society of Mountain Medicine (29)) method has the advantage of not being based solely on the measurement of core temperature, and it can be performed by non-medical personnel (7).

Severely hypothermic patients have been successfully resuscitated even after several hours of asystolic cardiac arrest. The current record for the lowest core temperature from which a victim has been resuscitated in accidental hypothermia is $13.7^{\circ} \mathrm{C}$ (30). In the above staging criteria, $13^{\circ} \mathrm{C}$ has been arbitrarily chosen as the lower limit of viability based upon this case report.

Clearly the principal clinical challenge is in differentiating a Stage IV from a Stage V victim; that is a victim who is apparently dead, but potentially salvageable, as opposed to a victim in whom all attempts at resuscitation would be futile. Staging is thus relevant for several reasons in the pre-hospital setting. Firstly rescuers might be subject to lethal hazard due to tactical or environmental factors (e.g. in an avalanche scenario there is often the threat of a secondary avalanche). Attempts at resuscitation in the field may therefore subject a team to unnecessary risks. Secondly, in the instance of multiple victims from an avalanche burial, or a maritime incident with many victims in the water, it would be vital to allocate resources according to clinical status and needs, and to prioritise the order for evacuation of victims.

\section{Clinical Differentiation In Severe} Hypothermia - The On-Site Triage Of Victims

An obvious lethal injury is a contraindication to resuscitation. The following table gives a

guide as to the clinical features that may differentiate Stage IV from Stage V:

The measurement of serum potassium will be performed at the nearest medical facility and may be a criterion for either pronouncing life extinct, or for determining that resuscitation should continue and that the patient should be transported to definitive care, if such facilities are not immediately available (31). It may be possible in the future to determine serum potassium in the field by point-ofcare testing (e.g. iSTAT ${ }^{\otimes}$, Abbott Laboratories. Abbott Park, Illinois, U.S.A.) $(8,32)$.

The avalanche scenario illustrates the practical application of such guidelines, but also highlights the complexity of performing triage in the field. If the burial time is short - $35 \mathrm{~min}$ utes or less - the absolute priority is to remove the located victim from the snowpack as rapidly as possible, but with due concern for mechanical injury to the vertebral column or extremities. Prevention of asphyxia is critical, as it has been shown that survival after burial under snow, without an air pocket for greater than 35 minutes is impossible. Upon rescue, this victim is managed according to standard trauma protocols and pre-hospital critical care 
or resuscitation is instituted as necessary.

However, when burial time exceeds 35 minutes, managing severe hypothermia may become the key challenge in the extracted victim. Upon location within the snowpack, it is vital that the victim is dug out carefully and not dragged from the snow in a hasty attempt to commence resuscitation. Clues to their clinical status may be present which must be preserved if at all possible, and rough handling may provoke fatal dysrythmias. If the victim is unconscious, but is breathing and has a perfusing rhythm, then management is as for a Stage III victim. In the absence of vital signs, if the victim is in presumed cardiac arrest, and has a core temperature of $32^{\circ} \mathrm{C}$ or greater (i.e. is mildly hypothermic), then resuscitation follows Advanced Life Support (ALS) guidelines in the field. If successful then the patient is transported to a critical care facility. However, if this relatively warm patient fails to respond to field resuscitation of at least 20 minutes duration following extraction, then life may be pronounced extinct. In the case of prolonged burial when the victim's core temperature has dropped below $32^{\circ} \mathrm{C}$,

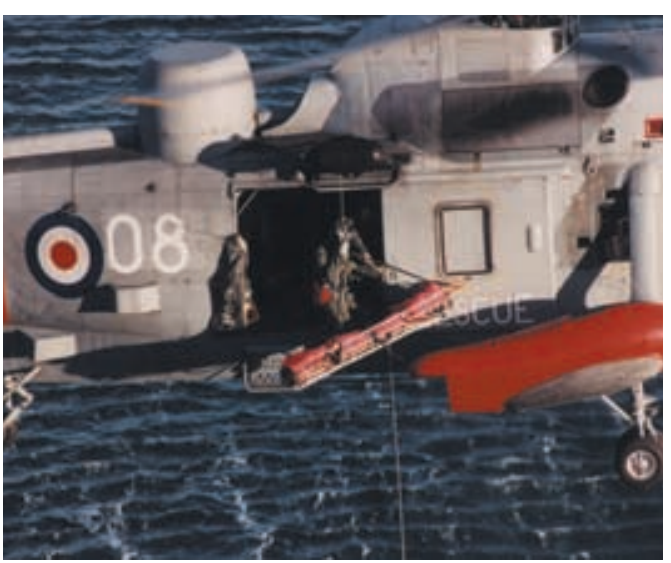

Stage IV hypothermia must be assumed provided that there is an air pocket around the face of the victim and that the airway is clear from obstruction due to ice or vomitus. Advanced life support (including endotracheal intubation) must be commenced, and the patient transported to definitive care. If however the airway is obstructed, then resuscitation is contraindicated, and life may be pronounced extinctError! Bookmark not defined.

Stage I Provide shelter and insulate from wind, rain or snow. Encourage shivering or exercise to generate heat. Give hot sweet drinks and food. Evacuation from the field is not mandatory, but should be considered if there is the suspicion of an occult injury or comorbidity that may have precipitated the hypothermic condition, such as a toxicological ingestion.

Stage IIThis patient is not shivering, and is vulnerable to life-threatening dysrythmias if handled roughly or inappropriately. He should be nursed horizontally in the side position to protect the airway (unless of course there is the suspicion of a spinal injury), and he should be warmed in the field. If the gag-reflex is present and the patient can swallow without risk of aspiration, then give hot sweet drinks and food. Disposition is to a hospital with an intensive care facility (ICU). This is of particular importance in the case of the avalanche victim who has suffered a period of complete burial, and the maritime victim who has been submersed, but survived (formerly referred to as "near-drowning"). Both are subject to possible late respiratory complications in the form of pulmonary oedema or acute respiratory distress syndrome (ARDS), or aspiration pneumonitis (33).

Stage III This patient will have a reduced level of consciousness, and will be on the cusp of suffering a potentially fatal dysrythmia. Safe patient handling is vital to preserve haemodynamic stability. It may be judged prudent to intubate and ventilate the patient, both to protect the airway and to optimise ventilation. Siting an intravenous line may be problematic due to peripheral vasoconstriction, but this is essential for the administration of the drugs necessary for rapid sequence induction (RSI) of anaesthesia, which will be necessitated if the patient's protective laryngeal reflexes are preserved despite his reduced level of consciousness. There are risks to intubation in that ventricular fibrillation may be provoked by laryngoscopy $(34,35)$ and the time required to perform the procedure may prolong extrication and evacuation. Measures to rewarm and insulate against further loss of heat must be employed. Disposition is to an institution capable of active rewarming - preferably with cardiopulmonary bypass (CPB) or extra-corporeal membranous oxygenation (ECMO) facilities.

Stage IVThis patient is severely hypothermic and apparently dead. Deep tendon reflexes are absent, and the pupils are fixed and dilated. Cardiopulmonary resuscitation (CPR) must be instituted immediately with the caveat that once commenced, it must be continued uninterrupted through to definitive care $(36,37)$. The rationale for this is that at very low temperatures it may be difficult to confirm ventilation or cardiac activity and initiation of CPR may trigger VF. To then cease CPR would be a fatal insult to the patient.

\section{Advanced Life Support In Hypothermia}

Intubate and ventilate, employing protective ventilatory strategies (high positive end-expiratory pressure (PEEP), low tidal volume) $(38,39)$. Palpate the carotid pulse and observe the ECG trace if possible, for up to 60 seconds before concluding that there is no cardiac output. If the victim is pulseless, or even if there is any doubt, then start chest compressions immediately. The ratio of ventilations to chest compressions is the same as for a normothermic patient. Intravenous fluids should be warmed, even pre-hospital if possible. Fluid 
should be $0.9 \%$ saline or $5 \%$ dextrose in saline. Ringer's lactate (Hartmann's solution) should be avoided because hepatic metabolism of lactate may be diminished leading to increased lactic acidosis (40). Epinephrine has been shown experimentally to improve coronary perfusion pressure in pigs, but not survival, in hypothermic cardiac arrest $(41,42)$. Epinephrine should be withheld in both the field, and in the hospital until the core temperature exceeds $30^{\circ} \mathrm{C}$, a) because the adrenoceptor is less responsive at low temperatures and b) because decreased drug metabolism may lead to potentially toxic plasma concentrations of any drug given repeatedly (14). Amiodarone is similarly affected (43). Once $30^{\circ} \mathrm{C}$ is reached during rewarming, the intervals between doses should be doubled until core temperature approaches normal when standard protocols should be used. Arrhythmias other than VF tend to resolve spontaneously as the core temperature increases. Bradycardia is usually physiological and does not require pacing unless persistent after rewarming. Defibrillation may be attempted pre-hospital, but must be limited to three shocks, even if VF or ventricular tachy- cardia (VT) persists, until the core temperature is greater than $30^{\circ} \mathrm{C}(44,45)$.

\section{Afterdrop}

Afterdrop is defined as the continued fall in the core temperature, after removal from the cold stress, and it may even occur during rewarming. It is relevant to the management of hypothermia because further cooling of the heart lowers the threshold for VF (46). The magnitude of afterdrop depends on the following factors: conductive heat loss along tissue thermal gradients (i.e. between the core of a muscle where heat is greater than at the cooler periphery of the skin) $(47,48)$, convective heat loss through changes in peripheral blood flow (where cold peripheral tissue becomes increasingly perfused as rewarming proceeds, leading to a 'dilution' of heat) (49) and local metabolic heat production in the periphery. It has been shown experimentally that core temperature may continue to drop by $2^{\circ}$ in the hypothermic victim, even after removal from the cold stress, when shivering is inhibited pharmacologically (by IV pethidine) (50), and one review has shown afterdrop values as high as $5^{\circ} \mathrm{C}(36)$.

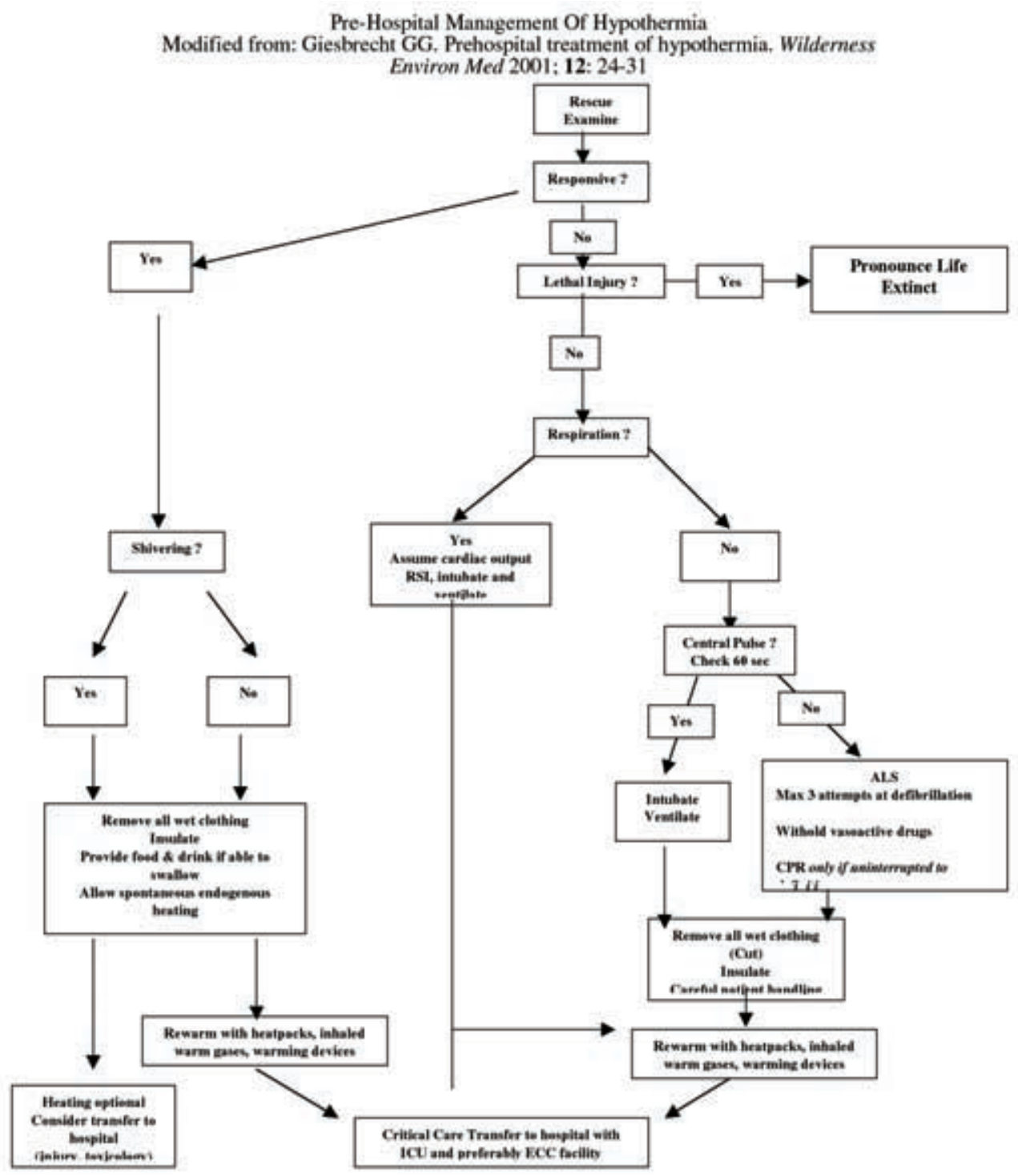

Fig 1.Resuscitation Guidelines According To Clinical Staging Of Hypothermia 


\section{Circum-Rescue Collapse}

There are many clinical examples of victims being rescued from cold stress (usually from cold water immersion) in an apparently stable and conscious condition, only to undergo a secondary or circum-rescue collapse, with symptoms ranging from syncope to ventricular fibrillation and cardiac arrest (51). Deaths have been described just before, during, or soon after rescue, as well as up to 24 hours after rescue (52-54). It is proposed that vertical removal from cold water results in a precipitous fall in blood pressure due to venous pooling in the lower limbs, inadequate coronary blood flow, and myocardial ischemia that possibly precipitates ventricular fibrillation. Golden et al. demonstrated decreases in aortic blood pressure and central venous pressure during vertical lifting by helicopter strop from cold water. This has led to the widespread practice of using a double strop (under the arms and knees), or a rescue litter, which can raise a victim in a more horizontal position. The same principles apply to the handling of the hypothermic victim in the terrestrial setting - the conscious hypothermic skier lying horizontal in a crevasse may experience circum-rescue collapse if suddenly manoeuvred into the vertical position for winch extraction.

\section{Insulation And Rewarming}

General measures include removal from the cold stress, gentle patient handling and removal of all layers of wet and damp clothing. Clothing should be cut from the moderate or severely hypothermic victim so as to minimise rough handling or changes in posture. In the field the victim should be insulated from the ground and from the wind, rain or snow. Rewarming is endogenous (encouraging the patient to shiver or exercise and produce their own heat), passive external (blankets in a warm room, allowing endogenous heat production to gradually warm the patient - suitable only for conscious victims with mild hypothermia), active external (heat packs, convective warming blankets) or active internal (warmed intravenous fluids, warmed humidified air/oxygen mixes, gastric, pleu-

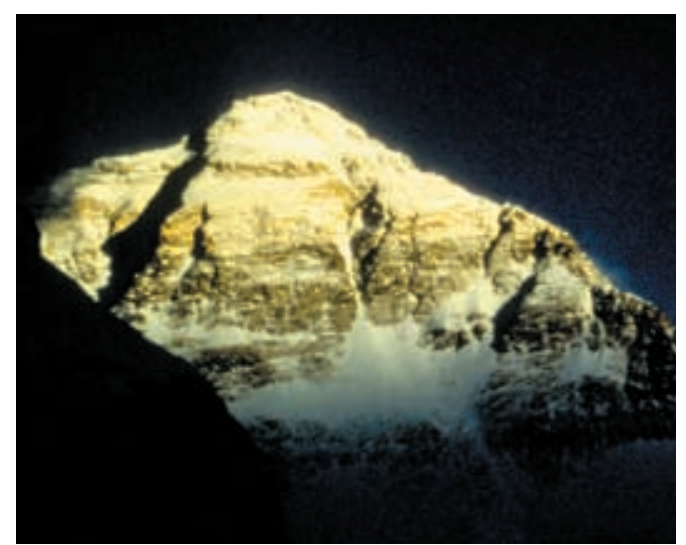

ral, peritoneal or bladder lavage with warmed fluids and ultimately extracorporeal blood warming by veno-veno haemodialysis (e.g. Prisma ${ }^{\circledR}$ system, Gambro Hospal Ltd, Huntingdon, Cambridgeshire, UK), $\mathrm{CPB}$, or ECMO.

\section{Pre-Hospital Rewarming}

There is much confusion regarding whether rewarming should or should not be initiated in the field in the moderate or severely hypothermic victim. It is important to distinguish rewarming from CPR. It may be desirous to withhold CPR during a rescue until it is possible to continue it uninterrupted through to definitive care; however it is imperative to prevent any further cooling of the victim because of the phenomenon of afterdrop as described above. The heart must not be allowed to cool any further - the threshold for VF will be lowered. Active warming must commence on the hypothermic victim in the field, with the caveat that patient handling is safe and controlled. The most practical method of active warming in the field is to place heat packs on the skin near to major blood vessels (neck, thoracic inlet, axillae, abdomen and groin) (55). Five to seven packs should be sufficient. Proprietary chemical packs may be used, or packs can be improvised by filling bottles with boiling water. These must however be covered to prevent thermal burns on the patient's skin. The patient must wear a warm cap to prevent heat loss through the scalp, and is then wrapped in one or more dry sleeping bags and insulated from the elements by an insulating roll-mat and sac that is impervious to wind and rain. Warmed, humidified air/oxygen mixes have previously been advocated for active field rewarming $(56,57)$, but their thermal advantage has been shown to be minimal (58-60). There is no reason to preclude inhalation warming, either alone or in combination with other methods, but it appears to convey no thermal advantage and so the space and weight occupied by such an item in the rescue kit might be better utilised. The Norwegian charcoalburning Heatpac ${ }^{\circledR}$ (Standard Telefon og Kabelfabrik, Oslo, Norway) does provide some thermal advantage through convective heating around the torso (61). Warming blankets utilising forced air (BairHugger ${ }^{\mathbb{B}}$, Arizant Inc, Eden, Prairie, MN55344, USA) and resistive heating technologies (Geratherm Rescue System ${ }^{\circledR}$, Geratherm Medical AG, Fahrenheitstrasse 1, 98716 Geschwenda, Germany) have been shown to be equally effective (62), and their use may be extended to the pre-hospital setting (63). There has been recent research into arteriovenous anastomosis (AVA) warming. Originally proposed in 1979 (64), when arms, forearms, lower legs and feet were immersed in water at 42 or $45^{\circ} \mathrm{C}$, rewarming rates were between 6.1 and $9.9^{\circ} \mathrm{C}$ per hour 
respectively (65). This method achieves rewarming by firstly opening the arteriovenous anastomoses in the fingers and toes; this then greatly increases the venous return to the heart via the superficial venous rete in the forearms and lower legs. Finally the warmed venous blood returns to the heart with minimal heat loss along the way, because the superficial veins are not in close proximity to the arteries. Whilst logistically this method of rewarming could not be performed at the incident site, it could easily be done at an expedition base camp, or on board a ship or yacht. A similar procedure has been performed where a water-perfused blanket was applied to a single forearm and hand in a subatmospheric pressure environment (66), attempting to mechanically distend blood vessels in the hand and forearm, and thus enhance AVA warming. Grahn et al.(66) claimed a 10 fold increase in the rate of warming compared to external warming alone, and it has been applied in the field to four

Hospital Management Of Hypothermi Modified from: Rousseau JM. Marsigny B. Cauchy E et al. Hypothermie en traumatologie. Ann Fr Anesth Réanim 1997; 16: 885-94.

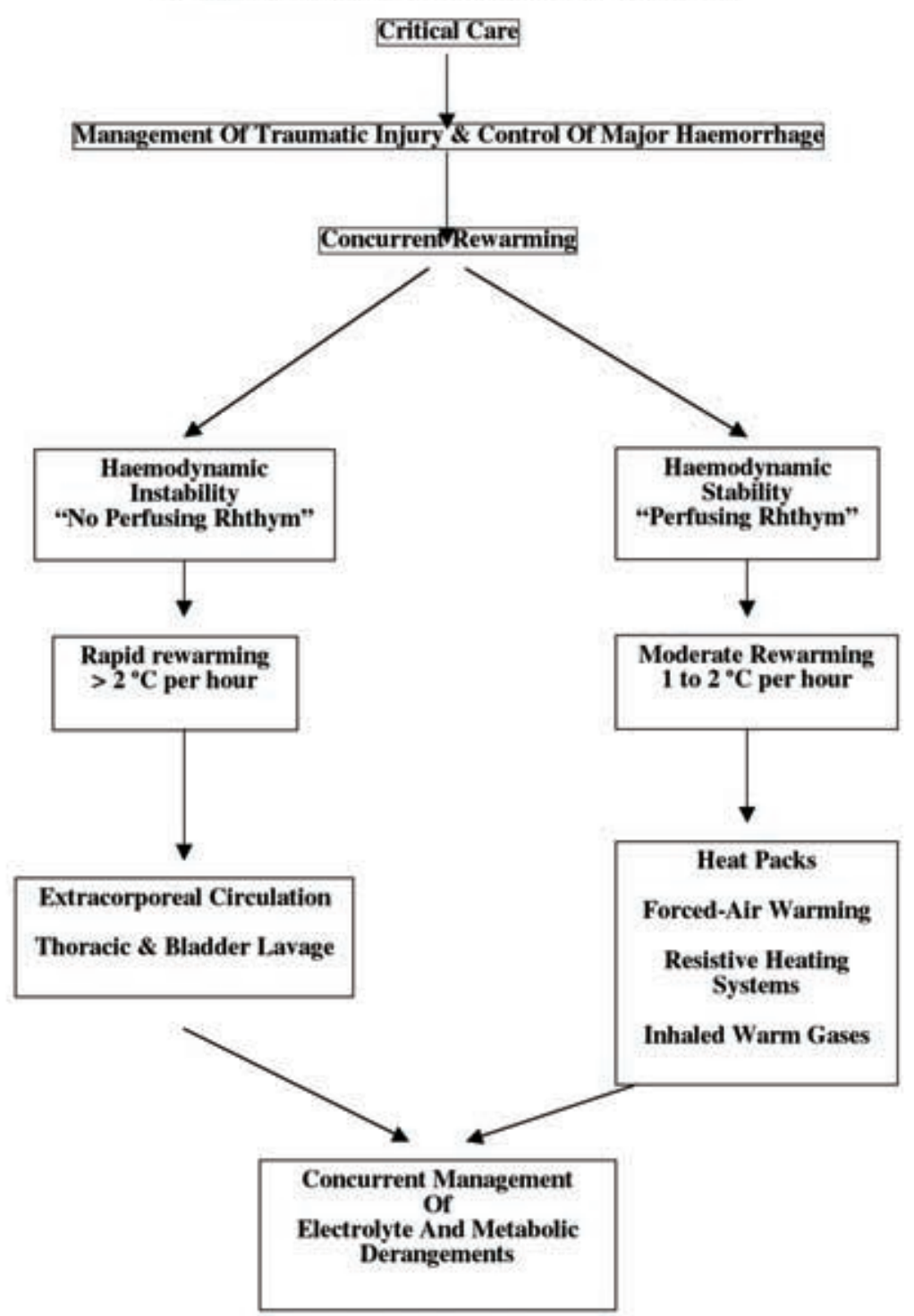

Fig 2. In-Hospital Critical Care.
Norwegian mildly hypothermic soldiers (67). However other workers have discounted the efficacy of enhanced AVA warming (68) and so it cannot be recommended in the absence of further evaluation. Whole-body immersion in hot water is contraindicated as a method of rewarming. This form of rapid surface warming will cause massive vasodilatation and hypotension, and is likely to provoke dysrythmias and cardiovascular collapse.

The in-hospital management of hypothermia follows the primary survey - resuscitation - secondary survey doctrine, but the resuscitation phase is modified as discussed, in light of the physiological derangement caused by hypothermia. The priorities are oxygenation and ventilation. However cardiovascular stability will only be achieved through arresting the drop in core temperature and establishing a safe and steady rate of rewarming. Correction of metabolic and electrolyte disturbances and intravenous fluid replacement runs concurrently. The secondary survey must not delay this process; nevertheless occult injury, sepsis or toxicological insult must be rigorously sought and managed. The depth of the core temperature does not dictate the method, or rapidity of rewarming the presence or absence of a perfusing rhythm is the critical deciding factor. Even in the patient with severe hypothermia, but with a perfusing rhythm, forced-air rewarming has been shown to be an effective method of rewarming leading to eventual discharge with a very good functional recovery $(69,70)$. This is simple and non-invasive and can be instituted in any emergency department (ED) or ICU. Mean rewarming rates are between 1 and $2^{\circ} \mathrm{C}$ per hour $(69,70)$, and this is safe because it allows physiology to normalise gradually.

However, in the case of cardiorespiratory arrest with severe hypothermia, the priority is to restore a perfusing rhythm, and the rate of rewarming must be rapid - in excess of $2^{\circ} \mathrm{C}$ per hour - and achieved by invasive means (21). In an institution without CPB or ECMO facilities, the options for extracorporeal (ECC) warming of blood are limited to venoveno haemofiltration $(71,72)$, or else pleural, peritoneal and bladder lavage with warmed fluids may be used to internally warm the heart and major blood vessels. Thoracic lavage (TL) may be accomplished either by thoracotomy (open TL) or tube thoracostomy (closed TL). A recent review of the literature has shown it to be effective and a safe alternative if $\mathrm{CPB}$ or ECMO facilities are not available, and the patient cannot be transferred to such a facility (73). Two large bore chest tubes are inserted into one or both hemithoraces. The first is placed anteriorly and superiorly (i.e. second to fourth intercostal space in the midclavicular line) and the second tube in a more posterior and inferior location (i.e. fifth to sixth intercostal space in the mid-posterior axillary line). Sterile saline at $40-42^{\circ} \mathrm{C}$ is 
infused into the anterior tube and allowed to passively exit via the posterior tube. A commercial warmer or countercurrent fluid warmer/infuser such as the Level $1^{\circledR}$ (Level 1 Inc. 160 Weymouth St, Rockland, MA 12370 U.S.A.) may be used. Upon completion of rewarming, the superior chest tube should be removed and the inferior tube left in place to allow for complete thoracic drainage. Rewarming rates of 5 to $7^{\circ} \mathrm{C}$ per hour can be achieved with haemofiltration or closed TL, but external chest compressions must continue throughout the resuscitation with both methods, until there is a return of spontaneous circulation (ROSC).

However, the gold standard for the resuscitation of the severely hypothermic victim in cardiorespiratory arrest is $\mathrm{CPB}$ or ECMO (74-77). Rewarming rates are as high as $10^{\circ} \mathrm{C}$ per hour. Survival to discharge with an excellent neurological function is possible even after prolonged asystolic cardiac arrest of one to two hours duration $(30,75)$. Success rates vary, but may be as high as $64 \%$ in patients who are not asphyxiated prior to becoming hypothermic; in contrast, submersed patients who have drowned and then become hypothermic, or avalanche victims who have asphyxiated before becoming hypothermic have a very poor prognosis (78). In the case of the severely injured hypothermic patient, there are methods of ECC that offer an alternative to full heparinisation of both the ECC circuit and the patient's circulatory system; this group of patients may already be coagulopathic upon admission to the ED, and to then formally anticoagulate them to perform ECC rewarming would be to heap insult upon injury (79). Once ROSC has been achieved, it is recommended, despite the lack of formal studies, that standard strategies for post resuscitation care be employed including mild hypothermia (10). There is no evidence to support the routine use of steroids, nor of antibiotics, unless there is co-existent sepsis (80).

Finally in determining the correct disposition for the patient, a balance has to be struck between the journey time entailed in a critical care transfer, the risk of further cooling of the patient (perhaps provoking a fatal dysrhythmia, or lowering to a core temperature from which resuscitation is impossible), the vulnerability of the patient during the transfer and the advantages offered by advanced tertiary care facilities.

\section{Summary}

Hypothermia is a multi-system disorder that significantly increases morbidity and mortality in the injured patient. It is an environmental hazard that can kill in its own right. The most difficult differentiation and management decisions are likely to be with victims in Stage II or Stage III hypothermia. Following successful rescue in these cases, arresting any further cooling of the core tem- perature, instituting rewarming strategies and careful patient handling will be the key factors in reducing morbidity and mortality.

\section{References}

1. O'Sullivan ST, O'Shaughnessy M, O'ConnorT P F Baron Larrey and cold injury during the campaigns of Napoleon. Ann Plast Surg 1995;34:446-449.

2. Golden F St C, Hervey, G R. The After Drop And Death After Immersion In Cold Water. In: JM Adam (ed) Hypothermia Ashore And Afloat. Aberdeen: Aberdeen University Press, 1981.

3. Lind J. An Essay On The Most Effectual Means Of Preserving The Health Of Seamen In The Royal Navy. London: D Wilson, Plato's Head, 1762.

4. Currie J. The Effects OfWater Cold And Warm As A Remedy For Fever. In: Appendix II, Treatment Of Shipwrecked Mariners. London: Cadell and Davis, 1798.

5. Beesley L. The Loss Of The Titanic. London: Philip Allen, 1912.

6. Elsensohn F (ed) Consensus Guidelines On Mountain Emergency Medicine And Risk Reduction. Lecco: Casa Editrice Stefanoni, 2002.

7. Brugger H, Durrer B, Adler-Kastner L. On-site triage of avalanche victims with asystole by the emergency doctor. Resuscitation 1996;31,11-16.

8. Brugger H, Durrer B, Adler-Kastner L et al. Field management of avalanche victims. Resuscitation 2001;51:7-15.

9. Durrer B, Brugger H, Syme D. Advanced challenges in resuscitation: Special challenges in ECC: hypothermia. Resuscitation 2001;50:243-245.

10. Soar J, Deakin CD, Nolan JP et al. European Resuscitation Council Guidelines For Resuscitation 2005. Section 7d. Hypothermia. Resuscitation 2005;67S1:S144-146.

11. Weinberg AD. Hypothermia. Ann Emerg Med 1993;22(2):370

12. Mattu A, Brady WA, Perron AD. Electrocardiographic manifestations of hypothermia. Am F Emerge Med 2002;20:314-26.

13. Holzer M, Behringer W, Schorkhuber W et al. Mild hypothermia and outcome after CPR. Hypothermia for Cardiac Arrest (HACA) Study Group. Acta Anaesthesiol Scand Suppl 1997;111:55-58.

14. Reuler JB. Hypothermia: pathophysiology, clinical settings, and management. Ann Intern Med 1978; 89:519-27.

15. Valeri CR, Cassidy G, Khuri S et al. Hypothermia induced reversible platelet dysfunction. Ann Surg 1987;205:175-81.

16. Staab DB, Sorensen VJ, Fath JJ et al. Coagulation defects resulting from ambient temperature-induced hypothermia. F Trauma 1994;36:634-38.

17. Luna G, Maier R, Pavlin EG et al. Incidence and effect of hypothermia in severely injured patients. $\mathcal{F}$ Trauma 1987;27:1014-18.

18. Gunning KA, Sugrue M, Sloane D et al. Hypothermia and severe trauma. Aust NZ F Surg 1995;65(2):80-2.

19. Johnson JW et al. Evolution in damage control for exsanguinating penetrating abdominal injury. $\mathcal{f}$ Trauma 2001;51:261-71.

20. Steineman S, Shackford SR, Davis JW. Implications of admission hypothermia in trauma patients. $\mathcal{f}$ Trauma 1990;30:200 - 2 .

21. Rousseau JM, Marsigny B, Cauchy E et al. Hypothermie en traumatologie. Ann Fr Anesth Réanim 1997;16:885-94.

22. Pugh LGCE. Cold stress and muscular exercise, with special reference to accidental hypothermia. $\mathrm{Br}$ Med F 1967;2:333-37.

23. Tikuisis P, Eyolfson DA, Xu X et al. Evidence of shivering fatigue: verification of a predictive model. Proceedings of theInternational Conference On Physiological And Cognitive Performance In Extreme Environments. 2000; Canberra, Australia. Australian Institute Of Sport; 2000:115-117.

24. Giesbrecht GG. Prehospital treatment of hypothermia. Wilderness Environ Med 2001;12(1): 24-31. 
25. Tikuisis P. Prediction of survival time at sea based upon observed body cooling rates. Aviat Space Environ Med 1997;68:441-48.

26. Walpoth BH, Galdikas J, Leupi F et al. Assessment of hypothermia with a new "tympanic" thermometer. $\mathcal{F}$ Clin Monit 1994;10(2):91-6.

27. Lefrant JY, Muller L, de La Coussaye JE et al. Temperature measurement in intensive care patients: comparison of urinary bladder, oesophageal, rectal, axillary, and inguinal methods versus pulmonary artery core method. Intensive Care Med 2003;29(3):414-8.

28. Robinson J, Charlton J, Seal R et al. Oesophageal, rectal, axillary, tympanic and pulmonary artery temperatures during cardiac surgery. Can $\mathcal{F}$ Anaesth 1998;45(4):317-23.

29. Durrer B , Hypothermie im Gebirge: Ärztliche Maßnahmen am Unfallort. Österreichisches. J. für. Sportmedizin 1991;2:50-54.

30. Gilbert M, Busund R, Skagseth A et al. Resuscitation from accidental hypothermia of $13.7^{\circ} \mathrm{C}$ with circulatory arrest. Lancet 2000;355: 375-76.

31. Larach MG Accidental hypothermia. Lancet 1995; 345:493-498.

32. Mair P, Kornberger E, Furtwängler W et al. Prognostic markers in patients with severe accidental hypothermia and cardiocirculatory arrest. Resuscitation 1994;27:47-54.

33. Brugger H, Falk M, Adler-Kastner L. Avalanche emergency. New aspects of the pathophysiology and therapy of buried avalanche victims. Wien Klin Wochenschr 1997;109(5):145-59.

34. Schneider SM. Hypothermia: from recognition to rewarming. Emerg Med Rep 1992;13:1-20.

35. Reuler JB. Hypothermia: pathophysiology, clinical settings, and management. Ann Intern Med 1978; 89:519-27.

36. Giesbrecht GG. Cold stress, near drowning and accidental hypothermia: a review. Aviat Space Environ Med 2000;71:733-752.

37. Steinman AM. Cardiopulmonary resuscitation and hypothermia. Circulation 1986;74:IV.29-32.

38. The acute respiratory distress syndrome network. Ventilation with lower tidal volumes as compared with traditional tidal volumes for acute lung injury and the acute respiratory distress syndrome. $N$ Engl f Med 2000;342:1301-8.

39. Moran I, Zavala E, Fernandez R et al. Recruitment manoeuvres in acute lung injury/acute respiratory distress syndrome. Eur Respir F Suppl 2003;42:37s$42 \mathrm{~s}$

40. Aun CST. Thermal disorders. In: Oh TE (ed) Intensive Care Medicine 4th edn. Oxford: Butterworth Heinemann, 1997.

41. Krismer AC, Lindner KH, Kornberger R, et al. Cardiopulmonary resuscitation during severe hypothermia in pigs: does epinephrine or vasopressin increase coronary perfusion pressure? Anesth Analg 2000;90: 69-73.

42. Kornberger $\mathrm{E}$, Lindner $\mathrm{KH}$, Mayr VD, et al. Effects of epinephrine in a pig model of hypothermic cardiac arrest and closed-chest cardiopulmonary resuscitation combined with active rewarming. Resuscitation 2001;50:301-8.

43. Stoner J, Martin G, O'Mara K et al. Amiodarone and bretylium in the treatment of hypothermic ventricular fibrillation in a canine model. Acad Emerg Med 2003;10:187-91.

44. Southwick FS, DalglishS P.H. Jr. Recovery after prolonged asystolic cardiac arrest in profound hypothermia: a case report and literature review. FAMA 1980;243:1250-3

45. Ujhelyi MR, Sims JJ, Dubin SA et al. Defibrillation energy requirements and electrical heterogeneity during total body hypothermia. Crit Care Med 2001;29:1006-11.

46. Covino BG, Beavers WR. Effect of hypothermia on ventricular fibrillatory threshold. Proc Soc Exp Biol Med. 1957;95:631-634.

47. Golden F St C, Hervey GR. The mechanism of the after-drop following immersion hypothermia in pigs. F Physiol 1977;272:26-27.
48. Webb P. Afterdrop of body temperature during rewarming: an alternative explanation. $\mathcal{f} A p p$ Physiol 1986;60:385-390.

49. Giesbrecht GG, Bristow GK. A second postcooling afterdrop: more evidence for a convective mechanism. F Appl Physiol 1992;73:1253-1258.

50. Giesbrecht GG, Goheen MSL, Johnston CE et al. Inhibition of shivering increases core temperature afterdrop and attenuates rewarming in hypothermic humans. F Appl Physiol 1997;83:1630-1634.

51. Golden FStC, Hervey GR, Tipton MJ. Circumrescue collapse: collapse, sometimes fatal, associated with rescue of immersion victims. 7 Roy Nav Med Serv 1991;77:139-149.

52. McCance RA, Ungley CC, Crosfill JWL et al. The Hazards to Men in Ships Lost at Sea, 1940-44. In: Medical Research Council Special Report Series. Report 291. London: Her Majesty's Stationery Office, 1956.

53. Keatinge WR. Death after shipwreck. Br Med J $1965 ; 25: 1537-1541$.

54. Golden FStC. Death after rescue from immersion in cold water. $\mathcal{F}$ R Nav Med Serv 1973;59:5-7.

55. Hamilton RS, Paton BC. The diagnosis and treatment of hypothermia by mountain rescue teams: a survey. Wilderness Environ Med 1996;7:28-37.

56. Weinberg AD. The role of inhalation rewarming in the early management of hypothermia. Resuscitation 1998;36:101-104.

57. Lloyd EL. Accidental hypothermia. Resuscitation 1996;32:111-124.

58. Mekjavic IB, Eiken O. Inhalation rewarming from hypothermia: an evaluation in $\_20^{\circ} \mathrm{C}$ simulated field conditions. Aviat Space Environ Med 1995; 66:424-429.

59. Ducharme MB, Kenny GP, Johnston CE et al. Efficacy of forced-air and inhalation rewarming in humans during mild ( $\mathrm{Tco}=33.9^{\circ} \mathrm{C}$ ) hypothermia. In: Shapiro Y, Moran DS, Epstein Y (eds) Environmental Ergonomics: Recent Progress and New Frontiers. London: Freund Publishing Co, 1996.

60. Lloyd EL. Airway rewarming in the treatment of accidental hypothermia: A review. $\mathcal{F}$ Wilderness $M e d$ 1990;1:65-78.

61. Hultzer M, Xu X, Marrao M et al. Efficacy of torso rewarming using a human model for severe hypothermia [abstract]. Proceedings of the World Congress on Wilderness Medicine 1999; Whistler, Canada: Wilderness Medical Society, 1999.

62. Matsuzaki Y, Matsukawa T, Ohki K et al.Warming by resistive heating maintains perioperative normothermia as well as forced air heating. $\mathrm{Br} \mathcal{F}$ Anaesth 2003;90(5):689-91.

63. Negishi C, Hasegawa K, Mukai S et al. Resistive heating and forced air warming are comparably effective. Anesth Analg 2003;96(6):1683-1687.

64. Vanggaard L, Gjerloff CC. A new simple technique of rewarming in hypothermia. Int Rev Army Navy Air Force Med Serv 1979;52:427-430.

65. Vanggaard L, Eyolfson D, Xu X et al. Immersion of distal arms and legs in warm water (AVA rewarming) effectively rewarms hypothermic humans. Aviat Space Environ Med 1999;70:10811088.

66. Grahn D, Brock-Utne JG, Watenpaugh DE et al. Recovery from hypothermia can be accelerated by mechanically distending blood vessels in the hand. f Appl Physiol 1998;85:1643-1648.

67. Soreide E, Grahn DA, Brock-Utne JG et al. A noninvasive means to effectively restore normothermia in cold stressed individuals: a preliminary report. $\mathcal{F}$ Emerg Med 1999;17:725-730.

68. Smith CE, Parand A, Pinchak AC et al. Failure of negative pressure rewarming (Thermostat ${ }^{\mathrm{TM}}$ ) to accelerate recovery from mild hypothermia in postsurgical patients. Anesth Analg 1999;89:15411545

69. Kornberger E, Schwarz B, Lindner $\mathrm{KH}$ et al. Forced air surface rewarming in patients with severe accidental hypothermia. Resuscitation 1999;41:105-11. 
70. Roggla M, Frossard M, Wagner A et al. Severe accidental hypothermia with or without hemodynamic instability: rewarming without the use of extracorporeal circulation. Wien Klin Wochenschr 2002;114:31520.

71. Broderson HP, Meurer T, Bolzenius $\mathrm{K}$, et al. Haemofiltration in very severe hypothermia with favourable outcome. Clin Nephr 1996;45:413-15.

72. Spooner K, Hassani A. Extracorporeal rewarming in a severely hypothermic patient using venovenous haemofiltration in the accident and emergency department. F Accid Emerg Med 2000; 17:422-424.

73. Plaisier BR. Thoracic lavage in accidental hypothermia with cardiac arrest - report of a case and review of the literature. Resuscitation 2005;66: 99-104.

74. Walpoth $\mathrm{BH}$, Walpoth-Aslan BN, Mattle HP, et al. Outcome of survivors of accidental deep hypothermia and circulatory arrest treated with extracorporeal blood warming. N Engl F Med 1997;337:1500-505.

75. Silfvast T, Pettila V. Outcome from severe accidental hypothermia in Southern Finland - a 10-year review. Resuscitation 2003;59:285-90.
76. Moser B, Voelckel W, Gardetto A et al. One night in a snowbank: a case report of severe hypothermia and cardiac arrest. Resuscitation 2005;65(3):365-8.

77. Tiruvoipati R, Balasubramanian SK, Khoshbin E et al. Successful use of venovenous extracorporeal membrane oxygenation in accidental hypothermic cardiac arrest. ASAIO $72005 ; 51(4): 474-6$.

78. Farstad M, Anderson KS, Koller ME et al. Rewarming from accidental hypothermia by extracorporeal circulation. A retrospective study. Eur J Cardiothorac Surg 2001;20(1):58-64.

79. Kirkpatrick AW, Garraway N, Brown DR et al. Use of a centrifugal vortex blood pump and heparinbonded circuit for extracorporeal rewarming of severe hypothermia in acutely injured and coagulopathic patients. F Trauma 2003 Sep;55(3):40712.

80. Safar P. Cerebral resuscitation after cardiac arrest: research initiatives and future directions [lpubished correction appears in Ann Emerg Med 1993; 22:759]. Ann Emerg Med 1993;22:324-49. 